\title{
Placement of Expandable Intratracheal Silicon Stent for Riedel's Thyroiditis
}

Ersin Gurkan DUMLU', Fahri YETISIR' ${ }^{1}$ Murał Baki YILDIRIM' ${ }^{1}$, Mehmet Tokaç' ${ }^{1}$ İbrahim

Kılınç ${ }^{1}$, Şeflka Burçak Polat ${ }^{2}$, Tülin Gümüș ${ }^{3}$, Mehmet KILIC ${ }^{4}$

From the Department of General Surgery', Department of General Endocrinology²,

Department of Anesthesiology ${ }^{3}$, Ataturk Research and Training Hospital, Ankara 06800,

Turkey; Department of General Surgery ${ }^{4}$, Yıldırım Beyazıt University, Ankara 06800, Turkey.

Abstract:

Introduction: Riedel thyroiditis is a form of thyroiditis characterised by inflammatory proliferative fibrotic process leading to destruction of thyroid gland and its capsule until reaching the surrounding tissue.

Case Report: Herein, the placement of intratracheal stent along with surgical treatment is discussed in a patient of Riedel thyroiditis with pressure symptoms and nonresponsive to medical treatment.

Discussion: Patients usually present with hard enlarged mass in the neck and pressure symptoms. Surgical treatment may be required when tracheal and esophageal pressure symptoms occur. Since Riedel thyroiditis involves surrounding tissues as well, it prevents a thyroidectomy at surgical anatomic plane and increases the probability of injury to recurrent laryngeal nerve and parathyroid glands.

Conclusion: When pressure symptoms recur in patients with Riedel thyroidits, who were operated previously, the placement of intratracheal permanent stent should be kept in mind among treatment options.

Key words: Thyroiditis, Thyroidectomy, Parathyroid Glands, Stents, Trachea.

Introduction

Riedel thyroiditis is a form of thyroiditis characterized by inflammatory proliferative fibrotic process. It is a type of thyroiditis which destroys thyroid gland and its capsule until reaching the surrounding tissue $[1,2]$. Riedel thyroiditis (RT) was first recognized by Bernard Riedel in 1896 [3]. Only a few new cases have been described since then. Patients generally present with hard enlarged mass in the neck and pressure symptoms. The probability of misdiagnosis of malignity is high. RT is a self limiting benign lesion. Surgical treatment may be required when tracheal and esophageal pressure symptoms occur. Since RT involves surrounding tissues as well, it prevents a thyroidectomy at surgical anatomic plane and increases the probability of injury to recurrent laryngeal nerve and parathyroid glands. Herein, the placement of intratracheal stent along with surgical treatment in a case or RT who has pressure symptoms and does not respond to medical treatment is reported.

\section{Corresponding Author: Dr. Ersin Gurkan DUMLU}

Email: gurkandumlu@gmail.com

Received: August 6, 2013 | Accepted: September 4, 2013 | Published Online: September 20, 2013 This is an Open Access article distributed under the terms of the Creative Commons Attribution License (creativecommons.org/licenses/by/3.0)

Conflict of interest: None declared | Source of funding: Nil | DOl: http://dx.doi.org/10.17659/01.2013.0078 


\section{Case Report}

A 25 year-old male patient referred to a health center 8 months ago with the complaints of swelling in neck and shortness of breath. In CT examination carried out in this center, at the junction of thyroid left lobe isthmus, a heterogenous hypodense $63 \times 42$ $\mathrm{mm}$ lesion with ill defined borders was detected. In view of noncontributary fine needle aspiration cytology, thyroidectomy was planned. In operation, since the mass was very hard and its anatomical limits were not clear, incisional biopsy was done and operation terminated.

Since results of pathological examination were consistent with fibro adipose tissue, Riedel thyroiditis was considered and $40 \mathrm{mg} /$ day prednisolone and tamoxifen were initiated. Patient was invited to control visit three months later. In control CT, a heterogeneous hypodense lesion without marked contrast and which has irregular borders was observed at the junction of thyroid gland left lobe isthmus. It was at the size of $63 \times 42 \mathrm{~mm}$ and extended for about $6 \mathrm{~cm}$ cranio-caudally until suprasternal area. Cervical and supraclavicular LAP (lymphadenopathy) was observed. It was decided to maintain medical treatment and at the control visit three months later, when pressure symptoms and shortness of breath were observed to be aggravated. CT examination was performed and the size of the lesion was found to be $71 \times 47 \mathrm{~mm}$ and at this level, it was seen that fat planes between lesion and trachea and left sternocleidomastoid muscle were obliterated. Patient was transferred to ICU upon the aggravation of shortness of breath. latrogenic Cushing syndrome developed and upon the increase in shortness of breath, patient was referred to endocrinology department of our hospital for further investigation and treatment since operation carried high risk [Fig.1]. After the examination carried out by endocrinology department and thoracic surgery department, the decision to put perioperative intratracheal stent placement was considered.

Intratracheal general anesthesia was administered and thyroid lodge was entered upon the previous Cocher incision. Excessive adhesions attached to surrounding tissue were found. Adhesions were separated with sharp and blunt dissection. In exploration, it was determined that thyroid gland lost its own tissue and has turned into a fibrous tissue which surrounds trachea completely and reaches esophagus at the posterior and exerts pressure on trachea especially on the left side. In this condition, it was impossible to observe and conserve recurrent laryngeal nerve and parathyroids. Thyroid tissue anterior to trachea was excised and sent for pathological examination. Following hemostasis, a suction drain was placed at the thyroidectomy area and layers were closed respectively. Patient was extubated with muscles still relaxed. Thoracic surgery department placed a permanent selfexpandable intratracheal silicon stent [Fig.2]. Patient was wakened without any problem and transferred to Intensive Care Unit. When respiratory parameters were found to be normal in follow up, patient was transferred to endocrinology clinic on first day post operatively. In follow up in the clinic, no shortness of breath was observed and the patient was discharged. The pathological examination revealed thyroid tissue replaced by fibrosis and intense mononuclear and eosinophilic inflammation [Fig.3].

\section{Discussion}

Riedel thyroiditis (RT) is a thyroiditis characterized by inflammatory proliferative fibrosis [1,2]. RT occurs rarely, with an incidence varying between $0.04 \%$ and $0.30 \%$ in large thyroidectomy series $[1,4]$. The duration of time from the onset of symptoms to the time of diagnosis usually varies between 4-10 months [4]. Although most of the Riedel's thyroiditis patients are euthyroid, there are series reporting hypothyroidism at the rate of $25-29 \%$ [4]. There 
are no findings that it shortens life span. But a fatal case has been reported in the literature [5]. RT has no specific finding. Usually it presents as a hard goitre in physical examination leading to pressure symptoms. The most common symptoms are a mass causing discomfort at the anterior of the neck, dysphagia, dyspnea and the feeling of asphyxia in lying position [1,2]. This clinical table may sometimes mislead the physician and lead to the misdiagnosis of malignant thyroid neoplasm. The incipient symptoms of RT are similar to those of other thyroid diseases. Interestingly, these symptoms, high fever, sore throat and pain at the anterior region of the neck imitate subacute thyroiditis $[1,6]$. The patients with fibrotic thyroiditis are usually euthyroid. In the series of Schwaegerle et al, $64 \%$ of the patients were found to be euthyroid, $32 \%$ hypothyroid and $4 \%$ hyperthyroid [7]. RT has no typical laboratory finding. TG-Ab and TPO-Ab, which are at usually low titrations, may increase in patients with RT [1].It cannot be distinguished from other thyroiditis cases via ultrasonography. In fact, hypoechogenity is the common finding of all inflammatory diseases [8]. It is quite difficult to distinguish it from other malignant neoplasms due to homogenous and, hypoechoic nodule appearance which has involved thyroid capsule and infiltrated strap muscles [9]. In CT examination, adjacent, soft tissue invasion, pressure on trachea, and oesephagus and combination of the three is typical. In MRI, T1 andT2 sequences, homogenous hypointense appearance may be regarded as pathognomonic for RT [10]. For diagnosis of RT, cytological examination with fine needle biopsy is useless, as acellular or hypocellular results are possible. In the pathological examination of excisional biopsy, fibrotic thyroid with hyalinization areas is seen [11]. RT is a benign self limiting disease. However, surgical treatment is required when pressure symptoms develop. Yet, due to adhesions caused by inflammatory process and unclear surgical plane, surgeons usually try to avoid these operations. In some cases, fibrosis may have reached parathyroids and nerves. In

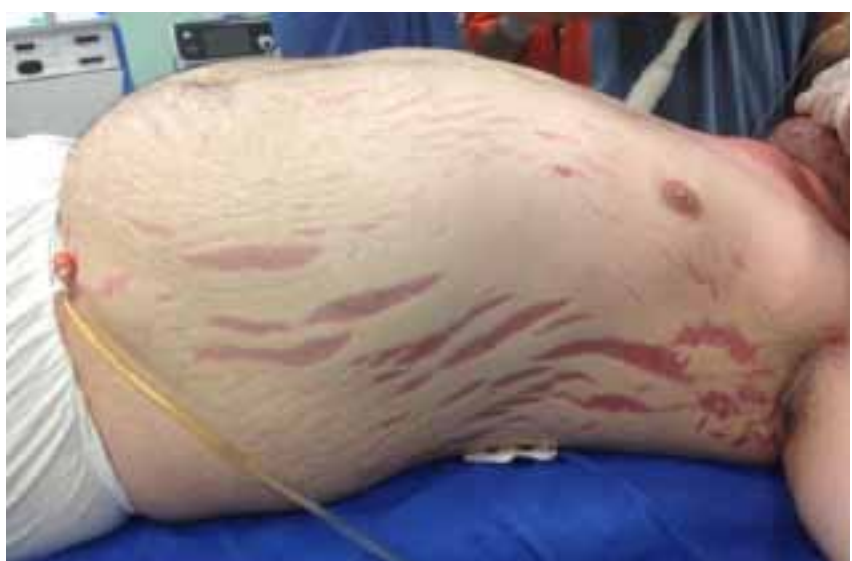

Fig. 1: Cushing Syndrome with strias.

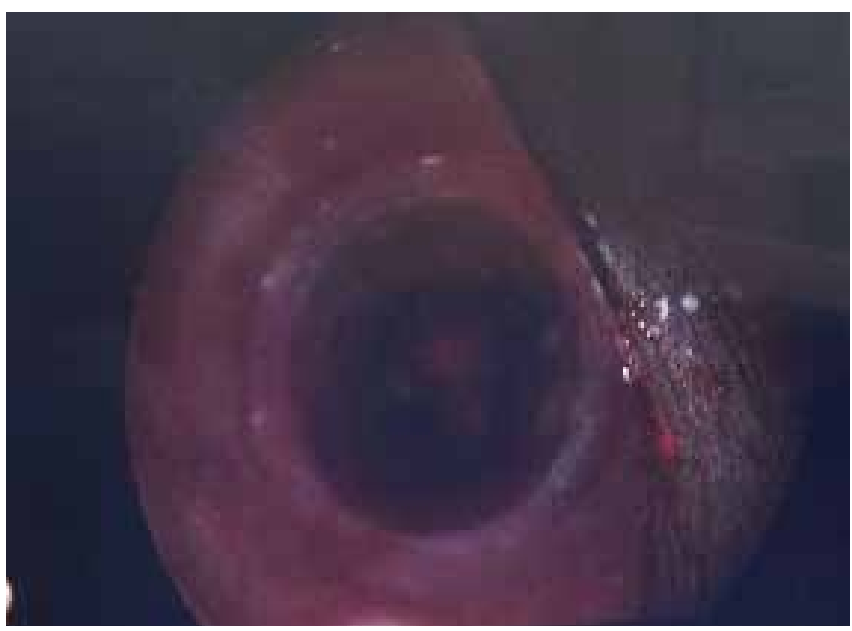

Fig.2: Endoscopic view of the placed stent.

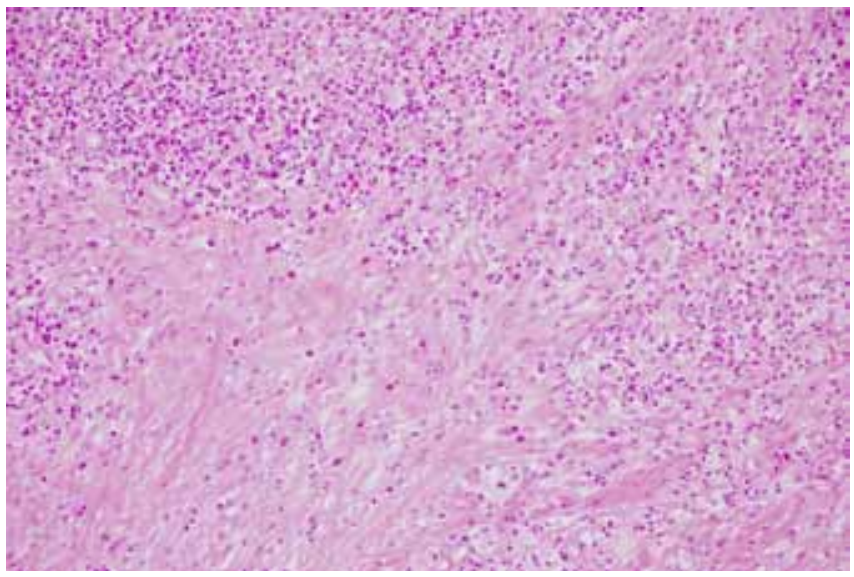

Fig.3: Microscopic view of the Riedel thyroitidis. 
these cases, complication is unavoidable. Surgical treatment should not aim to provide cure, but to improve pressure symptoms on trachea and esophagus. Usually, wedge resection at isthmus is adequate $[1,3]$. However, in our case, this method was tried but did not suffice.

Intratracheal stent is usually successfully placed in patients who develop postoperative intubation obstruction [12]. Other purposes of use are tracheomalacia, infection, tracheostomy damage and benign strictures that occur after transplantation [13]. In our literature search, we did not come across any reports of intratracheal stent placement for Riedel's thyroiditis. In our clinic, it was decided to place tracheal stent with reoperation. In the operation, we attempted to reach from anterior thyroid tissue to trachea, but since thyroid tissue surrounded all trachea until esophagus, sufficient resection was not possible. Intratracheal stent was placed and adequate tracheal openness was obtained. One of the greatest advantages of intratracheal stent is that it provides early postoperative relief [14], which also was observed in our patient. Two of the most important problems in long term follow-up are stent migration and occurrence of granulation tissue over the stent. For this reason, intermittent evaluation with fiber laryngoscope is necessary [14].

\section{Conclusion}

When pressure symptoms recur in patients with Riedel thyroidits, who were operated previously, the placement of intratracheal permanent stent should be kept in mind among treatment options.

\section{References}

1. Hay ID. Thyroiditis: a clinical update. Mayo Clin Proc. 1985;60:836-843.
2. Malotte MJ, Chonkich GD, Zuppan CW. Riedel's thyroiditis. Arch Otolaryngol Head Neck Surg. $1991 ; 117: 214-217$.

3. Riedel BMCL. Diechrnische, zur Bildung eiseharter Tumoren fuhrende Entzundung de Schilddruse. Verh Dtsch Ges Chir. 1896;24:101-105.

4. Woolner LB, McConahey WM, Beahrs $\mathrm{OH}$. Invasive fibrous thyroiditis (Riedel's struma). J Clin Endocrinol Metab. 1957;17:201-220.

5. Girod DA, Bigler SA, Coltrera MD. Riedel's thyroiditis: report of a lethal case and review of the literature. Otolaryngol Head Neck Surg. 1992;107:591-595.

6. Chopra D, Wool MS, Crosson A, Sawin CT. Riedel's struma associated with subacute thyroiditis, hypothyroidism, and hypoparathyroidism. J Clin Endocrinol Metab. 1978;46:869-871.

7. Schwaegerle SM, Baver TW, Esselstyn CB. Riedel's thyroiditis. Am J Clin Pathol. 1988;90:715-722.

8. Gooding GAW. Sonography of the thyroid and parathyroid. Radiol Clin North Am. 1993;9:975979.

9. Pérez Fontàn FJ, Cordido Carballido F, Pompo Felipe F, et al. Riedel thyroiditis: US, CT, and MR evaluation. J Comput Assist Tomogr. 1993; 17:324-325.

10. Ozgen A, Cila A. Riedel's thyroiditis in multifocal fibrosclerosis: $C T$ and MR imaging findings. Am J Neuroradiol. 2000;21:320-321.

11. Giampaolo Papi, Virginia A. Livolsi. Current Concepts on Riedel's thyroiditis. Am J Clin Pathol 2004;121 (Suppl 1):S50-S63.

12. Charokopos N, Foroulis CN, Rouska E, Sileli MN, Papadopoulos N. Papakonstantinou C. The management of post-intubation tracheal stenosis with self-expandable stents: early and long-term results in 11 cases; European Journal of Cardio-thoracic Surgery. 2011 ; 40:919-925.

13. Thornton RH, Gordon RL, Kerlan RK, LaBerge $J M$, Wilson MW, Wolanske KA, et al. Outcomes 
of tracheobronchial stent placement for benign disease. Radiology. 2006;240:273-282.

14. Wu CY, Liu YH, Hsieh MJ, Wu YC, Lu MS, Ko PJ, et al. Airway stents in management of tracheal stenosis: have we improved? ANZ J Surg. 2007;77:27-32. 